\title{
MURCS in a male?
}

\author{
Diana G Wellesley, Sarah F Slaney
}

\begin{abstract}
A man with Klippel-Feil deformity, unilateral renal agenesis, and azoospermia is presented as a possible case of MURCS.
\end{abstract}

(f Med Genet 1995; 32:314-315)

MURCS was first described in 1979 by Duncan et $a l,{ }^{1}$ who presented two females with Müllerian duct asplasia, renal agenesis, and cervical somite dysplasia. Since then there have been several reports ${ }^{2-4}$ of women with this constellation of anomalies, but no affected male has so far been described.

\section{Case report}

A 28 year old man was referred for investigation of primary infertility. He reported that he had experienced many urinary tract infections as a child and that investigations at that time showed a solitary right dysplastic kidney and left renal agenesis. Prophylactic antibiotic treatment was discontinued when he was 16 and since then he has remained free of infection.

He considered himself to be of short stature compared to his father and brother and complained of restricted neck movement, which had always been present although never investigated. His school performance was adequate and he was employed as a postman.

On examination his height was $173 \mathrm{~cm}$ (25th centile) and head circumference $56.5 \mathrm{~cm}$ (75th centile) with no facial dysmorphic features. His neck was short and very broad with a low posterior hair line and movement was limited in all planes. His palate, scapulae, upper limbs, sense of smell, hearing, and secondary sexual characteristics were all within normal limits. Examination of his genitalia showed the presence of both epididymi but with small, soft testes and thin vasa deferentia. His penis was of normal size with a correctly placed urethra. His sexual function was reported to be normal.

Investigations showed azoospermia and the aforementioned renal anomalies. $X$ rays showed block fusion of his vertebrae from $\mathrm{C} 6$ to $\mathrm{T} 8$, with multiple deformities of the neural arches both in this region and at the lumbosacral junction. In addition there were deformed ribs arising from $\mathrm{C} 7$ but the bone density was normal. His chromosomes analysed on peripheral blood and levels of $\mathrm{FSH}, \mathrm{LH}$ and testosterone were also normal. A planned testicular biopsy and exploration under anaesthetic was recently cancelled by the patient.

\section{Discussion}

Any explanation for the pathogenesis of the
MURCS association must take account of events in early embryonic development. One such hypothesis attributes the associated defects to an alteration of the blastema of the lower cervical and upper thoracic somites and pronephric ducts, which have an intimate spatial relationship in the fourth week (post conception) of development.

In the female, from the Müllerian ducts develop fallopian tubes, the uterus, and the upper two thirds of the vagina. The Wolffian duct, having given off its ureteric outgrowth, begins to atrophy before the end of the second month, but vestiges of it regularly persist as the hydatids of Morgagni.

In the male, the original cranial end of the Müllerian duct persists as the "appendix testis", the fused lower ends of the two ducts form the "uterus masculinus" in the prostate, and the remainder of the ducts usually disappears. The Wolffian duct becomes the epididymis, vas deferens, and seminal vesicles.

The ovary and testis have a common origin in the germinal epithelial cells and are indistinguishable until the seventh week.

Without a full examination under anaesthetic, it has not been possible to identify for sure all the derivatives of the Wolffian ducts in this patient. The epididymi were felt but not the seminal vesicles (which are often not palpable). He reported that he did produce some ejaculate. The vasa deferentia appeared thinner than expected but the relevance of this is uncertain in the presence of small testes. We are unable to assess the possible presence of any Müllerian duct remnants. $\mathrm{He}$ is, however, azoospermic for which no environmental cause can be identified.

Although no male has previously been described with this association of anomalies, $\mathrm{Pa}$ vanello $e t ~ a l^{5}$ presented a family in which three sisters each had Müllerian anomalies and their only brother was azoospermic. $\mathrm{He}$, however, refused further examination, and so no phenotypic details are available.

The gynaecological findings in female patients with the MURCS association are also known as the Mayer-Rokitansky-KusterHauser (MRKH) syndrome. According to Strubbe et $a l^{6}{ }^{6}$ typical findings include absence of the uterus and most of the vagina but with normal fallopian tubes. This would represent Müllerian duct hypoplasia rather than aplasia.

Müllerian duct hypoplasia would not affect fertility in our patient. We suggest that he has a degree of Wolffian duct hypoplasia (shown by his thin vasa deferentia and possibly absent seminal vesicles) that is responsible for his azoospermia. This would be analogous to the Müllerian duct hypoplasia found in female patients with MURCS 
We conclude that our patient has MURCS or WORCS and suggest that this association is not restricted to females but merely an easier diagnosis to make on account of the obvious, otherwise rare gynaecological abnormalities.

1 Duncan PA, Shapiro LR, Strangel JJ, Klein RM, Addonizio JC. The MURCS association: Mullerian duct aplasia, renal aplasia, and cervicothoracic somite dysplasia. $\mathcal{F}$ Pediatr 1979;95:399-402

2 Winer-Muram HT, Muram D, Wilroy RS, Cupp C. The concurrence of facioauriculovertebral spectrum and the
Rokitansky syndrome. Am f Obstet Gynecol 1984;149:56970 .

3 Greene RA, Boch MJ, Huff DS, Iozzo RV. MURCS association with additional congenital anomalies. Hum Pathol 1986;17:88-91.

4 Opitz JM. Vaginal atresia (von Mayer-Rokitansky-Kuster or MRK anomaly) in hereditary renal adysplasia (HRA). Am f Med Gene 1987;26:873-6.

5 Pavanello $R$ de CM, Eiger A, Otto PA. Relationship between Mayer-Rokitansky-Kuster (MRK) anomaly and hereditary renal adysplasia (HRA). Am 7 Med Genet 1998;29:845-9.

6 Strubbe EH, Cremers CWRJ, Willemsen WNP, Rolland R, Thijn CJP. The Mayer-Rokitansky-Kuster-Hauser (MRKH) syndrome without and with associated features: two separate entities? Clin Dysmorphol 1994;3:192-9. 